\title{
Experiencia de una niña de nueve años ante la separación parental
}

\author{
Diana E. Hernández-Hernández, Mg. ${ }^{a}$ \\ Universidad Nacional Autónoma de México, México \\ Patricia Trujano-Ruiz, Ph.D. ${ }^{b}$ \\ Universidad Nacional Autónoma de México, México
}

dianaed30@gmail.com

\section{Resumen (analítico)}

En este estudio cualitativo se describen y analizan los efectos de la separación parental, a través de la mirada y voz de una niña de nueve años. Se empleó como instrumento una entrevista semiestructurada y un análisis de resultados de tipo categórico. Las repercusiones observadas se clasificaron en efectos individuales como el manejo de la información y la construcción de explicaciones, así como una mayor independencia y mejora en su autoconcepto; y efectos en su entorno familiar, tales como la modificación en los vínculos afectivos con sus padres, dinámicas familiares más consistentes y mayores momentos de bienestar. Concluyendo que los infantes son participantes activos en la construcción de sus significados y que la separación de los padres puede permitir la generación de experiencias de crecimiento.

\section{Palabras clave}

Separación parental, divorcio, padres, niños, efectos, familia, significados, sujetos activos, participación infantil.

\section{Thesauro}

Tesauro de Ciencias Sociales de la Unesco.

\section{Para citar este artículo}

Hernández-Hernández, D. E., \& Trujano-Ruiz, P. (2021). Experiencia de una niña de nueve años ante la separación parental. Revista Latinoamericana de Ciencias Sociales, Niñez y Juventud, 19(2), 1-23. https://dx.doi.org/10.11600/rlcsnj.19.2.4684

\section{Historial}

Recibido: 05.06.2020

Aceptado: 13.10 .2020

Publicado: 28.04.2021

\section{Información artículo}

Este estudio de caso, realizado entre septiembre de 2018 y enero de 2019, se deriva de la investigación Separación parental: significados construidos por los y las niñas en torno a la experiencia, presentada por una de las autoras para optar por el título de Doctora en Psicología. Universidad Nacional Autónoma de México. Para dicha investigación se contó con el financiamiento de una beca proporcionada por el Consejo Nacional de Ciencia y Tecnología con número CVU 47618 (de agosto de 2016 a julio de 2020). Área: psicología. Subárea: psicología. 


\title{
Effects of parental separation: listening to a nine-year-old girl
}

\begin{abstract}
(analytical)
In this qualitative study, the effects of parental separation are described and analyzed through the voice and point of view of a nine-year-old girl. The authors used a semi-structured interview and categorical data analysis to identify these effects. The identified repercussions of the parental separation were classified into individual effects, such as information management and construction of explanations, as well as higher levels of independence and improvements in self-awareness. The authors also identified effects on the family environment such as modification of affective bonding with parents, more consistent family dynamics and increased moments of wellbeing. The study concludes that children perform an active role in the construction of their meaning and parental separation can facilitate the generation of self-growth experiences.
\end{abstract}

Keywords

Separation parental, divorce, parents, children, effects, family, meanings, active subjects, child participation.

\section{Efeitos da separação parental: ouvindo uma menina de nove anos}

\section{Resumo (analítico)}

Neste estudo qualitativo, são descritos e analisados os efeitos da separação parental através da visão e da voz de uma menina de nove anos. Utilizou-se como instrumento uma entrevista semiestruturada e uma análise dos resultados categóricos. As repercussões observadas foram classificadas em efeitos individuais, como gerenciamento de informações e construção de explicações, além de maior independência e melhoria de seu autoconceito; Os efeitos no ambiente familiar, como mudanças nos laços emocionais com os pais, dinâmicas familiares mais consistentes e mais momentos de bem-estar, concluindo que as crianças são participantes ativas na construção de seus significados. E, por último, que a separação dos pais pode gerar experiências de crescimento.

Palavras-chave

Separação parental, divórcio, pais, crianças, efeitos, familia, significados, sujeitos ativos, participação infantil

Información autoras

[a] Doctorante en Psicología, Universidad Nacional Autónoma de México. Maestra en Psicología, Universidad Nacional Autónoma de México. iD 0000-0001-6101-9811. H5: 0. Correo electrónico: dianaed30@gmail.com

[b] Maestra en Psicología, Universidad Nacional Autónoma de México. Doctora en Psicología Clínica, Universidad Autónoma de Barcelona. Profesora titular, Facultad de Estudios Superiores Iztacala, Universidad Nacional Autónoma de México. (iD) 0000-0003-4956-8724. H5: 18. Correo electrónico: trujano@unam.mx 


\section{Introducción}

a familia vive cambios psicosociales importantes en su estructura y en las funciomento de la separación parental resultado de disoluciones de uniones de parejas.

En México, el Instituto Nacional de Estadística Geografía e Informática (Inegi, 2019), reportó 147581 divorcios en febrero de 2019. Así, para muchos niños y niñas, convivir con sus padres por separado es una realidad vigente.

En sus inicios, la academia, con el término «divorcio» incluía tanto a los estudios relacionados con los miembros de la pareja como aquellos enfocados en las y los menores. Con el surgimiento del paradigma de la parentalidad —-segunda mitad de 1900- (Montagna, 2016; Núñez \& Vallejo, 2019), se propone la expresión separación parental, para hacer referencia al distanciamiento de los cónyuges motivado por la ruptura de la unión de pareja, pero en su calidad de padres para con los hijos e hijas. Dicho modelo se interesa en la interacción y en los efectos que pueden provocarles a estos y estas en su bienestar debido a que el contacto y la relación con sus progenitores puede verse interferida a partir de esta disolución (Fariña et al., 2017). Estas primeras investigaciones abordaban las consecuencias en los infantes a través de modelos explicativos del déficit o la patología (Sánchez \& Bolaños, 2018).

Actualmente las propuestas teóricas indican que la manera de experimentar la separación dependerá de múltiples factores contextuales, tanto físicos como del orden de lo simbólico; cuyas consecuencias aún tienden a ordenarse bajo una clasificación binaria de positivo/negativo o de ganancias/pérdidas (Brand et al., 2017).

Dentro de tales factores se encuentra la manera de llevar a cabo la separación por parte de los adultos y la explicación ofrecida a los infantes, ya que ambos tienen una relación directa con la forma de construir los significados relacionados con la ruptura conyugal de los padres y con las nuevas condiciones familiares, lo que contribuye con la manera de afrontar esta situación (Barea et al., 2015; Maes et al., 2012). Siendo el carácter 
de la separación y la experiencia de los menores, dos factores importantes en este proceso (Brand et al., 2017).

Para Brand et al. (2017) y Morgado y Cairós (2015), la consistencia en el vínculo e interacción de los padres hacia los y las menores son prioritarios en el proceso de adaptación a la nueva configuración familiar. Pérez y Luján (2015) destacan la importancia de una relación estrecha y afectuosa a la par de una supervisión firme y consistente de parte de los cuidadores. La cantidad de cambios, pero, sobre todo, la manera de llevarlos a cabo, incide en el modo de afrontar este trance por parte de los infantes (Ling, 2016), en donde la reorganización de las funciones parentales y el establecimiento de una relación coparental cooperadora desempeñan un papel fundamental junto con una transición moderada en las rutinas y actividades de su cotidianidad.

Estas repercusiones pueden ser de diversa naturaleza y magnitud de acuerdo con el tiempo transcurrido después de la separación parental. Algunos estudios abordan las acaecidas después de dos años - a mediano y largo plazo-, tiempo en el que se considera se alcanza la adaptación de los y las menores a estas nuevas condiciones de vida (Núñez \& Vallejo, 2019), en las que se destacan comúnmente los acontecimientos más visibles para los adultos. Otros estudios - aun escasos - retoman los testimonios infantiles para conocer su experiencia (Brand et al., 2017; Maes et al., 2012; Smart, 2006) en diferentes periodos de tiempo tras la separación; siendo necesaria la elaboración de una reconstrucción en retrospectiva de sus vivencias, en las que la distancia temporal, los nuevos rasgos madurativos y sus vivencias presentes pueden interferir.

Por ello, para abonar al panorama que se tiene de este fenómeno, resulta relevante y enriquecedor investigar la experiencia de las y los niños desde su mirada y voz, durante los primeros momentos tras la separación, para así identificar sus vivencias más significativas; aquellas en las que requieren apoyo y aquellas que obstaculizan o facilitan su ajuste a la nueva realidad familiar.

\section{Niños y niñas como sujetos activos de sus vivencias}

Estos hallazgos muestran el estado de vulnerabilidad al que se exponen las y los menores ante esta vivencia; empero, con frecuencia se desestima o subestima su capacidad para afrontarla y para ser partícipes activos en ella. Sin embargo, los y las niñas, además de internalizar los acontecimientos de su entorno, les otorgan sentido y coherencia, a la par de ser actores de su individualización (Gómez-Mendoza \& Alzate-Piedrahíta, 2014). 
Los conceptos de infancia y niñez son construcciones sociales, narraciones que han sufrido modificaciones a través de la historia (Aries, 1987) y, aun cuando implican aspectos de índole biológica, la caracterización y actuación hacia ellos corresponde a un fenómeno social contextualizado (Gómez-Mendoza \& Alzate-Piedrahíta, 2014). Los marcos referenciales son empleados para interpretar, objetivar y legitimar sus vivencias parte de paradigmas adultocéntricos (Lane et al., 2019). Como consecuencia, los y las niñas a menudo son considerados objetos dentro de las investigaciones; se habla sobre ellos, pero no con ellos, invisibilizando su capacidad de transmitir sobre la realidad que experimentan y construyen en sus distintos espacios de interacción.

Recientemente se ha reconocido su participación en los procesos sociales, lo que promueve pensarlos y mirarlos como actores (Caro et al., 2017). Ello posibilita que sean significados como agentes expertos en sus vivencias, con plena dignidad humana, reconocidos como tales por diversas áreas en la sociedad (Cabrera, 2017), con la capacidad de tomar decisiones al estar plenamente motivados e informados sobre su participación (Hart, 1993; Thomas, 2020). Esto favoreció el traslado de los estudios sobre niños y niñas a aquellos con y por los y las niñas (Rovetta-Cortés, 2017), atendiendo y escuchando sus opiniones, para intentar comprender sus experiencias al recuperar sus propios testimonios (Graham et al., 2015).

Respecto a los enfoques de investigación sobre separación parental, la tendencia ha sido unidireccional y vertical, tanto en las dimensiones que se evalúan como en las estrategias metodológicas empleadas. Se habla de infantes desde los adultos, siendo percibidos los primeros como seres pasivos y en desarrollo (Lane et al., 2019), mientras los últimos como agentes activos. Por lo que es indispensable una aproximación de investigación bidireccional que enfatice la co-ocurrencia de influencia en ambas direcciones - de padres a hijos e hijas y viceversa- como un complejo sistema recíproco (Maes et al., 2012) ya que, como señalan Aguirre et al. (2000), los y las niñas son influidos por las instancias sociales como la familia, a la vez que son capaces de modificarlas. Por lo cual, cobra sentido continuar realizando investigaciones sobre este fenómeno, partiendo de una noción relacional-bidireccional que acepte a las y los infantes como participantes, cuyos actos y decisiones afectan su propia vida y la del grupo social del que forman parte (Hart, 1993).

En este tenor, este trabajo se sustenta en el construccionismo social, ya que admite la validez de las diversas y distintas interpretaciones sobre un fenómeno y reconoce que su legitimación dependerá del entorno contextual en el que se sitúe (Gergen \& Gergen, 2011). 
Pero, asumir a los menores como miembros informados sobre la realidad que viven y con la capacidad para comunicarla, demanda la escucha de sus opiniones y perspectivas (Sosenski, 2016) y, sobre todo, su legitimación (Rovetta-Cortés, 2017). Empero, para conseguirlo hay que ofrecerles alternativas metodológicas pertinentes para que puedan expresar sus vivencias.

Por ello, partiendo de las premisas de que la separación parental es un fenómeno relacional-bidireccional y que los niños y niñas son sujetos activos en este proceso, con la aptitud para dar cuenta de su experiencia, estimamos necesario un acercamiento distinto e indagar a través de su mirada y voz como protagonistas. De ahí que nuestra pregunta de investigación fuera: ¿cuáles son los efectos a corto plazo de la separación parental en la experiencia de una niña de nueve años? Para lograrlo, consideramos imprescindible una participación voluntaria en la investigación y el uso de una herramienta que favoreciera una comunicación espontánea sobre la separación parental.

\section{Método}

El objetivo del estudio fue describir y analizar los efectos a corto plazo que enfrentó una niña de 9 años por la separación parental. La niña colaboró voluntariamente. Perteneciente presumiblemente a un nivel socioeconómico medio-bajo, fue seleccionada de un grupo de cuarto grado de una escuela primaria pública. Los criterios de inclusión fueron que la separación parental estuviera consumada, que uno de los progenitores se hubiera marchado del hogar y que la niña no estuviera en un proceso de evaluación motivado por la asignación de la guarda y custodia o en un proceso psicoterapéutico motivado por la separación de sus padres.

\section{Diseño}

Estudio de caso intrínseco (Stake, 1999) y prospectivo que permite, por una parte, particularizar un fenómeno, posibilitando su realce y la comprensión de su singularidad; y, por otra, focalizar un número limitado de hechos y situaciones para abordarlos con profundidad y alcanzar su intelección holística y contextual (Neiman \& Quaranta, 2009). Bajo un enfoque cualitativo, que enfatiza «la naturaleza socialmente construida de la realidad, la relación íntima entre el investigador y aquello que se estudia y las restricciones contextuales que dan forma a la investigación» (Denzin \& Lincoln, 2012, p. 62). 


\section{Instrumento y materiales}

Entrevista semiestructurada diseñada ex profeso para el presente estudio; esta, en las y los menores, permite investigar cómo significan, piensan, perciben, actúan y sienten, favoreciendo el descubrimiento de aquello que no resulta evidente en la apariencia de su conducta y la exploración de los discursos que construyen a través de sus acciones o palabras (Delval, 2001).

La entrevista se organizó en tres momentos temporales: antes, durante y después de la separación, con diferentes ejes temáticos: vínculo con los padres, principales rutinas de la niña, noticia de la separación y efectos de esta. Todas las entrevistas fueron consentidas para ser grabadas en audio.

Como materiales se emplearon colores, hojas blancas y dibujos impresos, los cuales sirvieron para establecer y desarrollar la conversación, ya que es sensible a los intereses y habilidades de las y los menores, propicia su comodidad y suprime la amenaza que puede representar participar con adultos o que sean juzgados por lo que digan (Moscoso \& Díaz, 2018).

\section{Consideraciones éticas}

Daniela (nombre ficticio) y su madre indicaron su aceptación y firmaron un asentimiento y un consentimiento informado respectivamente. A ambas se les comunicó que era la niña quien decidía su participación, aunque su mamá ya hubiera aceptado. El anonimato se consiguió usando el nombre ficticio y la confidencialidad no comentando a su madre y a los integrantes de su centro escolar la información que brindó la niña.

Como parte de las consideraciones éticas también se procuró el uso de instrumentos y materiales pertinentes a las características del estadio de desarrollo de la niña, y se le brindó como retribución por su participación una sesión de devolución como cierre; en esta se subrayaron los recursos que posee y que le han permitido afrontar positivamente la separación de sus padres.

\section{Escenario, procedimiento y análisis}

El presente estudio se llevó a cabo dentro de las instalaciones de una escuela primaria pública, localizada en el Municipio de Tlalnepantla, Estado de México. Se empleó un lugar familiar para la niña, para aminorar la tensión que podía generarle la interacción con una adulta desconocida (Bernuz, 2019). 
Como primer paso se presentó la investigación y se obtuvo la aprobación de los directivos y, posteriormente, del profesor del grupo de la niña. Después se expuso el proyecto a los y las niñas, además de hacerles la invitación. Daniela señaló su deseo de participar, por lo que se llevó a cabo un encuentro con su madre en la que firmó el consentimiento informado. Luego, la menor firmó el asentimiento informado y se realizaron las entrevistas, entre los meses de septiembre de 2018 y enero de 2019. Al finalizar se realizó la sesión de cierre.

Transcritas las entrevistas, se procedió al análisis de la información mediante la identificación y creación de categorías al comparar los ejes temáticos de los tres periodos temporales del proceso de separación parental; ello que permitió su codificación-interpretación (Stake, 1999), a la luz del construccionismo social y de las características madurativas de la niña. De esta manera, se obtuvieron dos grupos amplios de repercusiones en la experiencia de la niña: efectos en el entorno familiar y efectos individuales.

\section{Resultados}

\section{Contexto de la separación}

Daniela es una niña de 9 años e hija única. Ella, su madre y su padre vivían en un departamento rentado dentro de una zona urbana considerada en México de interés social. La disolución de pareja fue de hecho, pues no contaban con un contrato matrimonial y acaeció dieciocho meses antes de la primera entrevista. Tenían escaso contacto con las familias de origen, más aún con las de la línea materna debido a que su padre no lo permitía.

La madre de Daniela tenía 29 años. Meses previos a la ruptura conyugal comenzó a laborar como empleada, lo que continúa haciendo. Actualmente cursa estudios universitarios. Cuando surgieron los conflictos de pareja, su madre se tornó irritable y llegó a abofetearla. Su padre, de 39 años, se desempeñaba como chofer foráneo, estando frecuentemente fuera de casa por periodos de hasta dos semanas, con descansos extensos -incluso de una semana- misma que pasaba en casa realizando actividades lúdicas que la niña disfrutaba. Su papá podía decidir que no asistiera a la escuela para que estuvieran juntos.

Con ambos progenitores mantenía una buena relación —aunque más próxima con su madre-; sin embargo, por el carácter explosivo de su padre y por infringirle una agresión física, Daniela tenía temor de que pudiera lastimarla cuando se enojaba. 
La estructura familiar de Daniela era patriarcal: su padre proveedor económico; su madre encargada del cuidado del hogar y de su hija; y el estilo de crianza autoritario, principalmente de parte de su padre.

Cuando comienza a trabajar la señora, le solicita a su pareja ayuda en las tareas domésticas, pero este nunca acepta. Surgen también entre ellos peleas constantes, en las que el señor llegaba a violentarlas de manera verbal e, incluso, física y psicológica. En una de sus discusiones este se marcha; su madre le insiste en que regrese, pero él se niega, lo que provoca en la señora una profunda tristeza. Daniela al verla le escribe una carta expresándole su cariño y apoyo, enfatizándole que ambas son un equipo. Acción que entiende su mamá como un parteaguas que le permite reconocer el ambiente de violencia en el que han vivido y al que han expuesto a su hija, lo que la anima a terminar definitivamente con esa relación.

\section{Efectos en su entorno familiar}

Cuando el padre de Daniela se marchó, sus encuentros con ella también disminuyeron. Esta situación la vivió con inquietud y desconcierto, pero no por el hecho mismo, pues ya estaba acostumbrada a las ausencias prolongadas de su papá, sino por el poco interés que le brindaba.

Ya tiene tiempo que no lo veo, como dos o tres meses o cuatro... Luego tarda mucho en contestar mis mensajes y no ha venido; y eso pues como que no me gusta mucho.

Y porque al pelear con su madre, se alejaba sin explicación alguna, y no cumplía con las actividades que habían acordado previamente.

Sí regresaron, pero después de dos días, tristemente; pero triste, pero triste, pero triste, pero tristemente se enojaron porque mi mamá se fue de viaje. Y entonces él se fue enojado; me dijo que él me iba a llevar a la escuela, y no, que me iba a ayudar en mi maqueta o algo así, y no, él es el que vio y me dijo eso y no me ayudó (...); papá ¿por qué te fuiste?, no te despediste de mí (pensó Daniela).

Esto obedecía a que sus progenitores ponderaron sus conflictos de pareja sobre el ejercicio de sus funciones parentales.

Ahora mi papá dice que ya ni un minuto quiere ver a mi mamá; así lo dice, ni por mí, dice mi papá. Cuando cumplí los nueve años, bueno antes, cuando todavía tenía ocho, me dijo 
que él ya no quería ver a mi mamá; que ni en mi cumpleaños, que mi cumpleaños sí me la voy a pasar con mi mamá, con mi mamá, si con él, sin nadie más.

Pero, la salida de su padre también tuvo un impacto benéfico para el ambiente familiar de la niña, pues dejó de experimentar tensión e inquietud en su cotidianidad, debido a los eventos violentos suscitados por su padre y dirigidos hacia ella o hacia su madre.

Cuando venía [su padre] había una pelea siempre, todos los días, no había un día que no.

Pues, aunque sus padres discutían al reencontrarse - ocasionando en Daniela sentimientos de desagrado y tristeza-, los sobrellevaba de mejor manera, pues podía retornar a un ambiente estable y consistente en sus dos contextos familiares (durante el día en casa de su abuela materna y por la noche en el departamento con su madre). En estos habitualmente se manejaban reglas claras y anticipadas acordes a su edad y comentadas con ella, lo cual le proporcionaba una sensación de seguridad ante el futuro inmediato.

Comíamos con mi abuela, bien rico, hasta me decía: «Qué hacemos de comer?»

Estos cambios en la estructura y en la organización familiar favorecieron que Daniela y su madre entraran en mayor contacto con la familia materna, quien se desempeñó con la niña como red de apoyo, de cuidado y de diversión.

Me adelantaron más en la escuela, me sacaron más a museos, acuarios; estoy con mi abuela.

Ello provocó también reajustes en actividades domésticas, escolares y lúdicas, que generalmente se organizaban con anticipación y por tiempos definidos en función de los horarios y tareas de la madre de Daniela; lo que en ocasiones limitaba y obstaculizaba las actividades de ocio entre ellas.

Mi mamá me pone un poco de menos atención; está muy estresada, muy apurada.

En tanto, la asistencia que recibió la madre de Daniela disminuyó su agobio por trabajar, estudiar y cuidar a su hija, generándose una mejor interrelación entre ellas. Empero, estas nuevas relaciones también suscitaron en la niña sentimientos penosos hacia algunos familiares maternos, al escuchar opiniones negativas sobre su padre. 
Mi abuela me dice que no me quiere [refiriéndose a su papá], que me quiere pisotear como una cucaracha (...); y yo me pongo triste y de que, no, no... [recuerda lo que pensó en ese momento] pero nada más lo quiero; pero él no me quiere pisotear como una cucaracha.

Por otra parte, en cuanto a la relación con sus progenitores, su papá continuó tomando decisiones sobre la niña sin consultar y sin poder ser cuestionado. Ella acataba sus órdenes - aunque no estuviera de acuerdo- por miedo a sus reacciones o a que fuera lastimada si lo desobedecía.

Cuando vivíamos siempre llegaba enojado (...). Un día casi le pega a mi mamá (...); traté de decirle que no le pegara, pero me dijo: «iVete a tu cuarto, vete a tu cuarto!», y por miedo me fui.

Esto pudo contribuir a la dificultad que Daniela mostraba para expresar lo que pensaba o sentía. Al preguntarle acerca de la posibilidad de comentarle a su madre sus sentimientos sobre la separación, señaló:

Mmm, no tengo el valor...; no sé qué pasaría... Me quedo trabada y digo otra cosa.

Lo anterior también contribuía a que constantemente sintiera temor de su padre. Comentó que aquello que temía de él era:

Que me haga algo malo, que le haga algo malo a mi mamá. De que cuando estoy con mi papá algunas veces se enoja, y no sé qué hago mal, pero me espanto y me regaña muy feo. Un día hasta me empujó y casi me pego con la máquina de coser.

Otro rasgo significativo es que no identificaba a su padre como una figura totalmente confiable, pues fácilmente rompía las promesas que le hacía.

Sí, en ese momento le dije que no le contara nada a mi mamá; se lo contó y no me gustó eso (...), porque era como una mentira, no fue una promesa (...). Sí, también me puso triste, porque mi papá no se despidió de mí; me puso triste (...). Se enojó y se fue; ni se despidió de mí.

Sin embargo, podía aceptar el afecto que tenía hacia su padre y su deseo de frecuentarlo, más no de vivir con él. 
Le obedezco a mi papá cuando se enoja y cuando está feliz, pues sí, nos divertimos (...), pues me gusta jugar con él.

En cuanto a la cercanía emocional que tenía con su madre, esta se incrementó tras la separación. Al preguntarle si le agradaba estar con su madre, respondió:

Mucho, ella me lleva a museos, al cine, me lleva al centro, me lleva a patinar, me lleva a los juegos y a los acuarios.

Daniela la identificó como figura de seguridad y confianza; generó con ella una relación más estrecha y afectuosa, a la par que recibía una supervisión consistente.

\section{Efectos individuales}

Dentro de los efectos individuales, uno de los retos difíciles para Daniela fue la falta de acompañamiento por parte de sus progenitores en la producción de significados en conjunto respecto a la ruptura conyugal y la separación parental. No recibió una explicación sobre lo que sucedía, generándole incertidumbre y desconcierto. Ella se percató por sí misma (y lo confirmó al tener acceso a las redes sociales de su madre y leer un mensaje de su padre), pero no fue capaz de preguntar lo que sucedía.

Vi cuando mi papá se llevó sus cosas; (...) se llevó sus cosas y dijo [a su madre] «jYo ya no te quiero ver!» (...), [y Daniela pensó] Mi papá se va, se va a separar de mi mamá (...). Pero qué va a pasar, se van a separar; no entiendo.

Yo no pregunto nada, ni a mi abuela, porque ella luego, luego: «Tus papás se separaron, sabías que y bla, bla, bla». Y mejor me quedo calladita y yo: «A ver, piensa Daniela, piensa por qué se habrán separado».

Esto fue consecuencia de ser considerada incapaz de entender la situación que vivía por parte de su familia, lo que constituyó un reto más a enfrentar.

Le dije a mi papá: «Papá ¿por qué te fuiste?» Me dijo: «Cuando seas más grande me entenderás...»

Daniela, además de tener inquietud por conocer lo que ocurría a su alrededor, también contaba con la aptitud para comprenderlo. Al cuestionarla respecto a su compresión de lo que sucedía si le hubieran ofrecido una explicación, comentó: 
Diría que sí (...), porque así mi mente se hubiera puesto a trabajar y hubiera entendido con más facilidad por qué se separaron.

También mostró interés por lo que podían hacer otros niños y niñas en su misma situación para aprender a vivir con sus padres separados. Expresó que ellos y ellas podrían:

Dejar de pensar en eso, de que hablaran por qué su mamá se separó de su papá...; salir con sus amigos..., tratar de pensar en otras cosas que no fuera eso.

Y aunque sus padres le brindaron escasa información sobre la separación parental, paradójicamente le compartieron aspectos sobre sus conflictos de pareja, lo cual la llevó a enfrentar momentos incómodos y dolorosos.

¿Qué está haciendo mal mi mamá? [es lo que piensa Daniela cuando su papá le hace comentarios sobre su madre], y yo no entiendo, no entiendo lo que está haciendo mal y él dice: «Está haciendo muchas cosas mal tu mamá». [Ella le pregunta] «Pero ¿qué cosas está haciendo mal mi mamá?» «Muchas» [responde su papá] y no me dice...; y me siento mal, porque mi mamá no está haciendo nada malo. Me tratan muy bien mis abuelos; me enseñan muy bien y todo.

Daniela fue considerada una confidente sobre las problemáticas de pareja, una aliada para lograr una reconciliación en el caso de su papá y una cómplice de actividades que realizó su madre y que no quería que se enterara su padre. Esta información la inclinó a guardar lealtad a ambos progenitores, a tener la esperanza de su reencuentro y a enfrentar desilusiones y sentimientos de culpa por no conseguirlo.

Pero no todos los desafíos que enfrentó Daniela ante la separación parental fueron negativos; hubo varios considerados positivos que le permitieron la adquisición de nuevos aprendizajes y prácticas dentro de su ambiente familiar.

Le ayudo a mi mamá a lavar los trastes, este, a tender la cama, doblar mi ropa, que es lo más aburrido.

Logros que consideraba también le serían funcionales en un futuro. 
Ya sé hacer cosas que mi mamá no me tiene que explicar, y de mis tíos aprendo muyyy rápido; me facilita las cosas [ayudarle a su mamá] para cuando yo sea grande y tenga mi casa y pueda hacer las cosas yo solita.

En este tenor, Daniela mostró sentimientos y acciones empáticos hacia los afectos y deseos de su madre. Deseaba que lograra viajar porque consideraba era su sueño. Al indagar por qué anhelaba que esto sucediera, respondió:

No sé, se siente bonito (...). Le dije: «No mamá, tú, si quieres ir, ve» [cuando se enteraron de que el papá de la niña no autorizaría la salida de la menor del país, como medida de presión a su madre para evitar que realizara ese paseo].

Percibió también la tristeza de su madre por el distanciamiento con su padre y el esfuerzo que le representaba estudiar, trabajar y cuidar de ella, y encauzó acciones para apoyarla. La animaba con cartas y dibujos, la alentaba en sus metas y colaboraba con quehaceres para aminorar su agobio.

Yo la apoyo mucho; mi mamá hace sus exámenes en casa, no me puede hacer de comer. Así es que yo me hago, me hago un huevito estrellado.

Así mismo, expresó solidaridad hacia su madre ante las situaciones derivadas del reajuste familiar. Al ser consciente del esfuerzo de esta, colaboró y buscó no representarle un exceso de trabajo. Daniela identificó que el bienestar de su madre repercutía en una mejora de su ánimo y, por tanto, en un trato más favorable hacia ella. Reconoció que el escaso tiempo que pueden pasar juntas se debía solo a las múltiples actividades de su madre y no a que esta no deseara estar con ella.

Mi mamá me pone un poquito de menos atención. Está muy estresada, muy apurada... Nada más por eso; por lo demás sí me pone atención.

Y aun cuando había momentos de tensión, Daniela podía valorar positivamente los cambios que enfrentó.

Ahora salgo más; voy a museos, voy a la universidad. Tengo muchos amigos. 


\section{Discusión}

Las categorizaciones binarias positivas/negativas, ganancias/pérdidas para explicar a nivel teórico la experiencia de la separación parental permiten abordar de manera simple este fenómeno; sin embargo, en la cotidianidad de los y las menores este suceso es un proceso que, como menciona Nuñez et al. (2017), desencadena modificaciones en distintas áreas de sus vidas, difíciles de disociar porque se entretejen (como ocurrió con Daniela).

Ciertamente, los efectos más visibles a corto plazo para los y las autoras son aquellos de naturaleza cuantitativa, es decir, los cambios de espacios, de personas, de rutinas, etcétera, así como aquellos de naturaleza cualitativa, como las modificaciones en las relaciones, los vínculos e interacciones entre progenitores-hijos/hijas y familia extensa y menores llegan a pasar desapercibidos. Lo anterior conlleva la idea de que la ausencia de los primeros y presencia de los segundos hacen de esta vivencia una experiencia poco significativa. Sin embargo, estos sucesos también llegan a desencadenar un impacto relevante en el bienestar emocional y familiar de los menores, como fue para Daniela.

En este tenor y retomando nuestra pregunta de investigación (¿cuáles son los efectos a corto plazo de la separación parental en la experiencia de una niña de nueve años?) pudimos responderla haciendo las siguientes observaciones. En primer lugar, como señala Gallego (2019), entre los cambios más visibles tras la separación parental está la salida de uno de los progenitores del hogar, que suele asumirse como perjudicial en sí mismo. Sin embargo, una familia constituida por un padre y una madre no garantiza el bienestar en los hijos e hijas, pues lo esencial para ellos y ellas no radica en que estén o no presentes, como ocurrió con Daniela, sino en la calidad de la interacción que pueden brindarles; ello dado que la disposición y el interés para participar y acompañarlos en sus diferentes escenarios y prácticas cotidianas permite la construcción del vínculo afectivo entre ellos y la generación de significados en torno a la convivencia y a los diversos aspectos de la realidad particular que comparten.

Dejar de vivir con uno de los progenitores desencadena algunas modificaciones. En el caso de Daniela encontramos dos de las señaladas por Ling (2016): reconfiguración de las relaciones familiares y creación/adaptación de nuevas prácticas y rutinas familiares, las cuales, en su mayoría, se concretaron en efectos positivos.

Dentro de las reconfiguraciones familiares, la dinámica de crianza autoritaria (Gallego et al., 2019) que enfrentaba la niña antes de la disolución fomentó en ella una constante 
subordinación, sensación de inseguridad y una actitud de obediencia constante, minimizando con ello su autonomía. Esto contribuyó para que significara la voz de los adultos como aquella que posee valor y poder de decisión y, ante la cual, no podía opinar. Situación que pudo trascender hasta considerarse incapaz de expresar lo que piensa o siente. Mientras que al cohabitar solo con su madre, pasó a una estrategia más cercana a la democracia, creando lo que Gergen y Gergen (2011) llamaron un sentido colectivo de lo que es y se debe hacer en una familia. Esta nueva configuración familiar fue resultado de practicar un modo distinto de dialogar e interrelacionarse, obteniendo también mayores posibilidades de negociación y escucha.

Respecto a construir nuevos vínculos e interacciones, en correspondencia con Maldonado y Torres de Vasconcelos (2015), Daniela conformó una mejor interrelación y vínculo con su madre. El diálogo entre ellas comenzó a reconstruirse desde otra perspectiva; compartieron más actividades afines y así, ambas conformaron un equipo. Su madre, al recibir apoyo, se encontraba menos abrumada, posibilitando una mejor interacción con la niña; esto confirma lo señalado por Gallego et al. (2019) acerca de que el bienestar de los progenitores se reflejaba en un mejor trato hacia los y las menores. En este sentido, conforme con Pérez y Luján (2015), consideramos que su madre se convirtió en una figura consistente y segura. Elementos en los que convenimos con Brand et al. (2017) al consideraros prioritarios en el proceso de adaptación a la nueva configuración familiar.

Esta nueva manera de conformar una familia también mejoró la dimensión socioafectiva en la niña brindándole, como manifiesta Gallego et al. (2019), mayor oportunidad para expresarse e incidir en una concepción distinta de sí misma, más favorable para su autoimagen y autoconcepto. Aunque es importante señalar que con su familia aún no lograba externar sus ideas y emociones sobre la separación y la convivencia con sus padres, durante la entrevista Daniela pudo hacer contacto y poner en palabras sus pensamientos y afectos; un paso importante en el proceso de significación.

Continuando con Ling (2016), Daniela inició nuevas prácticas y rutinas, siendo dos las más valoradas por la niña: tener paseos constantes a lugares que disfrutaba y acompañar a su madre a la universidad. Con esta última entró en contacto con nuevos adultos y niños(as), y percibió que las mujeres pueden desarrollarse profesionalmente y tener otros espacios de crecimiento personal fuera del ámbito doméstico y familiar; ello pudo dotarla de elementos para cuestionar las prácticas dominantes con las que había tenido contacto.

En tanto las repercusiones individuales que enfrentan a corto plazo los y las menores ante la separación parental, pueden llegar a ser poco evidentes para los adultos 
comparados con las modificaciones del ambiente familiar, debido a que los recursos o comportamientos que poseen para expresarlas no son fácilmente relacionadas con la separación de sus padres. Sin embargo, dichas repercusiones pueden constituir verdaderos desafíos para ellos.

$\mathrm{Al}$ igual que encontró Maes et al. (2012), identificamos que una de las consecuencias inmediatas e importantes para los menores es no contar con una explicación sobre lo que sucede con su familia, pues esta brinda la pauta para construir significados relacionados con este evento y con el reajuste familiar posterior. Ofrecer información clara, precisa y acorde a las posibilidades de comprensión de los niños y niñas les proporciona certeza respecto a lo que acontecerá a partir de ese momento y seguridad en sus progenitores como figuras de cuidado, protección y cariño. La significación de una vivencia se gesta en relación con el otro y, para los menores, los adultos cercanos, principalmente sus padres, tienen gran influencia para que puedan funcionar de mejor manera. Es así que, al igual que Gergen y Gergen (2011), consideramos que compartir marcos de referencia semejantes les permite brindar sentido y valor a su realidad.

Daniela fue capaz de esclarecer la realidad, formando conjeturas a partir de los acontecimientos que observaba. Por ello es indispensable, como señala Maes et al. (2012), que a los menores se les brinde una explicación; de lo contrario tenderán como afirma Brand et al. (2017), a generar alguna, que puede ser errónea. Al respecto convenimos con Gómez-Mendoza y Alzate-Piedrahíta (2014) en que la falta de explicación puede estar relacionada con la idea de los padres de que los menores no comprenden las situaciones de los adultos. En nuestro país culturalmente se tiene una concepción de los niños y niñas como seres imperfectos, incompletos e inmaduros, por lo que no pueden acceder al discernimiento de los fenómenos sociales, como lo es la separación parental. Y como asevera Caro et al. (2017), al encarnarse estos discursos en prácticas, el padre de la niña estimó que ella no podría entender lo que sucedía.

Por lo tanto, consideramos que la disyuntiva no reside en brindarles o no una explicación a los menores, sino en determinar qué información y de qué manera hay que proveérselas, pues la que requieren es la correspondiente a su calidad de hijo/hija. En ese tenor, al igual que Fariña et al. (2017), reconocemos que es indispensable que los progenitores dejen fuera a sus hijos e hijas de sus conflictos de pareja; de lo contrario, se puede dificultar el ejercicio de sus funciones parentales, como fue en este caso, la interferencia en la necesidad de contención que requería la niña ante estos cambios. A Daniela la hicieron partícipe de información que no le correspondía, exponiéndola, como expresa Gai- 
tán (2006), a un conocimiento social que no podía entender del todo y que le despertó sentimientos penosos.

Por otra parte, con frecuencia se asume la idea equivoca de que los y las menores - por su rasgo egocéntrico- únicamente están preocupados y ocupados en sus actividades infantiles; sin embargo, ellos y ellas son capaces de distinguir qué sucede, tanto en su entorno como en las personas que los rodean, así como de brindar ayuda y ser agentes de cambio. Daniela fue solidaria y empática hacia su madre con el propósito consciente de aminorar su tensión. Demostró ser una participante activa en la construcción de esta experiencia y una agente en la conformación de una nueva dinámica familiar. Además de ser, como señala Gómez-Mendoza y Alzate-Piedrahíta (2014), un actor en su proceso de individuación, pues reconfiguró la imagen que tenía de sí misma, generando significados nuevos como el de ser una persona eficiente que es capaz de proporcionar apoyo y asistencia a su madre; además, independiente y solidaria, pues el valor que le otorgó a las tareas que realizaba en casa trascendió su realización y mediante ellas formó equipo con su madre y contribuyó con la estabilidad familiar.

Los niños y niñas tienen la capacidad de observar los fenómenos que ocurren a su alrededor y de formarse una postura al respecto. Daniela fue capaz tanto de identificar las repercusiones poco favorables que le produjo la separación de sus padres como también de valorar los aspectos positivos. Esta tarea no es sencilla, ya que las consecuencias de este proceso no presentan una frontera claramente definida para los menores y el proceso no está libre de desafíos y tensiones.

Finalmente, es necesario señalar que con frecuencia se da un sentido trágico a la separación parental; pero hay ocasiones en que esta situación, como afirma Cabello (2014), constituye una alternativa de bienestar, de crecimiento personal y de desarrollo de autonomía. Y después de precisar el trance que enfrentó Daniela, podemos considerar que ella pertenece a uno de estos casos.

\section{Conclusiones}

La separación de los padres es un fenómeno complejo en el que participan factores de diversa naturaleza y que pueden llegar a propiciar efectos en distintos aspectos de la vida de los niños y niñas. La disolución de una pareja es una decisión solo de los adultos, pero la separación parental les concierne también a los y las menores, pues ellos son partícipes 
activos en la construcción de esta experiencia familiar. Empero, para poder aceptar su intervención, hay que modificar la idea errónea de que son seres pasivos que únicamente reciben el impacto de la voluntad de los adultos, para así poder reconocer y legitimar la capacidad que poseen para atender los acontecimientos sociales de su entorno, para formarse una opinión y una postura sobre ellos, así como para tomar decisiones y encauzar acciones.

Escuchar a los niños y las niñas nos permite conocer lo que piensan, sienten y necesitan; pero no como una condescendencia de los adultos, sino con respeto y promoción a su derecho de ser escuchados en aquello de lo que son partícipes. En este tenor, la separación parental es un fenómeno relacional-bidireccional; es decir, los padres y los hijos/hijas desde su lugar y condición aportan sentido y significados para configurar una experiencia determinada.

Actualmente se tiende a atribuir al hecho mismo de la separación parental un efecto catastrófico directo para los menores; y aunque para algunos puede constituir la posibilidad de vivenciar experiencias dolorosas que pueden derivar en repercusiones nocivas, para otros puede representar una oportunidad para reconfigurar diversos significados sobre la familia, para modificar los vínculos parentales y para entrar en contacto con otras redes de apoyo. Convirtiéndose así en un medio para acceder a un estado de bienestar tanto para los menores como para la familia en general.

Con esta investigación se logró un acercamiento a la complejidad de los niños y niñas en el proceso de construir experiencias con los adultos, desde su propia mirada y voz. Se mostró que es imprescindible comprender este fenómeno, pero ahora desde la perspectiva infantil, buscando para ello los recursos propicios que nos permitan aproximarnos a los sentidos que otorgan a sus vivencias.

Es primordial también no hablar de las vivencias infantiles en plural pues, al hacerlo, implícitamente se asume que los y las niñas enfrentan y configuran sus experiencias de manera semejante. Por lo que es fundamental apreciar su subjetividad dentro de su contexto familiar, social y cultural específico, para así poder matizar sus experiencias.

Las aportaciones en este estudio residen primeramente en abordar el tema de la experiencia ante la separación de los padres desde la narrativa en primera persona de una niña que vivió ese proceso, pues generalmente se habla desde la voz de los adultos. También en exponer a través de datos empíricos que los y las niñas poseen sus propias ideas y postura, logrando encauzar acciones respecto a este suceso de manera consciente. Por 
tanto, tienen la capacidad de ser sujetos activos en la configuración de un fenómeno social, como es la separación parental y la conformación de una nueva unidad y dinámica familiar.

Otra aportación fue mostrar la pertinencia de la estrategia metodológica (estudio de caso) y la postura teórica (construccionismo social) en la investigación de este fenómeno. La primera permitió profundizar en la vivencia de Daniela, dar cuenta de sus matices y visibilizar diversas repercusiones individuales a corto plazo, que a través de las investigaciones con grupos pasan desapercibidas. Mientras que con la segunda se consiguió empoderar su voz y presentar el panorama de una experiencia impregnada de diversos recursos y posibilidades, así como alejada de la patología. De esta manera, se favoreció en la niña una reflexión que le permitió resignificar su experiencia, identificar los aprendizajes obtenidos y destacar sus habilidades para afrontarla.

Algunas de las limitaciones en este estudio se encuentran en que solo se tomó el testimonio de la menor y no el de personas cercanas a ella; así mismo, el limitado tiempo que se le pudo dedicar a la participante. Ambas posibilidades pudieron haber enriquecido la información obtenida. Sin embargo, las condiciones de la investigación y de la institución educativa a la que pertenecía la niña lo impidieron.

Finalmente, aun se requieren investigaciones que profundicen en las experiencias infantiles, desde su mirada y voz, ante la separación de los padres en diferentes contextos y realidades; así como del estudio de los factores contextuales inmediatos a la ruptura conyugal que favorecen el ajuste de los niños a las nuevas condiciones familiares.

\section{Agradecimientos}

Al Consejo Nacional de Ciencia y Tecnología, por su apoyo para realizar los estudios de doctorado. Numero de CVU 47618.

\section{Referencias}

Aguirre, E., Durán, E., \& Torrado, M. (2000). Socialización: prácticas de crianza y cuidado de la salud. Centro de Estudios Sociales.

Aries, P. (1987). El niño y la vida familiar en el antiguo régimen. Taurus. 
Barea, S., Ben-Yahia, Y., Luque, C., \& Fernández-Molina (2015). Experiencias sobre separación y divorcio en tres aulas de educación infantil: una propuesta de intervención. Ensayos, Revista de la Facultad de Educación de Albacete, 3o(2), 173-187.

Bernuz, B. M. (2019). El derecho de la infancia a ser investigada correctamente. Papers. Revista de Sociología, 104(3), 381-402. https://doi.org/10.5565/rev/papers.2492

Brand, C., Howcroft, G., \& Hoelson, C. (2017). The voice of the child in parental divorce: implications for clinical practice and mental health practitioners. Journal of Child \& Adolescent Mental Health, 29(2), 169-178. http://doi.org/10.2989/17280583.2017.1345746

Burke, E., \& Crespi, T. (2015). Divorced fathers: Implications and consequences for children and families. Online Journal of Counseling \& Education, 4(4), 546-557.

Cabello, M. (2014). El significado que un grupo de mujeres puertorriqueñas le adscribe al divorcio en su vida: un estudio fenomenológico. Revista Griot, 7(1), 19-36.

Cabrera, D. E. (2017). Reflexión sobre la dignidad del niño y niña. Revista Colombiana de Bioética, 12(2), 90-100. https://doi.org/10.18270/rcb.v12i2.1924

Caro, P., Saracostti, M., Kinkead, A., \& Grau, M. O. (2017). Niñez y adultez: diálogos frente a tensiones familiares, laborales y del cuidado. Revista Latinoamericana de Ciencias Sociales, Niñez y Juventud, 15(1), 267-279.

Delval, J. (2001). Descubrir el pensamiento de los niños. Paidós.

Denzin, N., \& Lincoln, Y. (Coords.) (2012). Manual de investigación cualitativa. Gedisa.

Fariña, F., Pérez-Lahoz, Vázquez M., \& Seijo, D. (2017). Clima familiar y coparentalidad en familias con ruptura de pareja. Revista de Estudios e Investigación en Psicología y Educación, (5), 295-298. http://doi.org/10.17979/reipe.2017.0.05.2782

Gaitán, L. (2006). La nueva sociología de la infancia: aportaciones de una mirada distinta. Política y Sociedad, 43(1), 9-26.

Gallego, A., Pino, J., Álvarez, M., Vargas, E., \& Correa, L. (2019). La dinámica familiar y estilos de crianza: pilares fundamentales en la dimensión socioafectiva. Hallazgos, 16(32), 131-15o. http://doi.org/10.15332/2422409X.5093

Gergen, K., \& Gergen, M. (2011). Reflexiones sobre la construcción social. Paidós.

Gómez-Mendoza, M., \& Alzate-Piedrahíta, M. (2014). La infancia contemporánea. Revista Latinoamericana de Ciencias Sociales, Niñez y Juventud, 12(1), 77-89.

Graham, A., Powell, M. A., \& Taylor, N. (2015). Ethical research involving children: encouraging reflexive engagement in research with children and young people. Children \& Society, 29(5), 331-343. http://doi.org/10.1111/chso.12089

Hart, R. (1993). La participación de los niños: de la participación simbólica a la participación auténtica. Unicef. 
Instituto Nacional de Estadística y Geografía. (2019, 12 de febrero). Comunicado de prensa n. ${ }^{\circ}$ 104. https://bit.ly/3tYp3Go

Lane, D., Blank, J., \& Jones, P. (2019). Research with children: Context, power, and representation. Qualitative Report, 24(4), 693-704.

Ling, S. E. (2016). Reconfigured everyday lives of children from divorced-parent families in Singapore. Marriage \& Family Review, 52(1-2), 106-126. https://doi.org/f8q2

Maes, S., De Mol, J., \& Buysse, A. (2012). Children's experiences and meaning, construction on parental of divorce. Childhood, 19(2), 266-279. https://doi.org/dz2d8x

Maldonado, M., \& Torres de Vasconcelos, T. (2015). Divorcio y alienación parental en las voces de los alienados. Investigaciones Cualitativas en Salud, (1), 501-506.

Montagna, P. (2016). Parentalidad socio-afectiva y las familias actuales. Derecho PUCP, (77), 219-233. https://doi.org/10.1880o/derechopucp.201602.010

Morgado, B., \& Cairós, A. (2015). Aproximación a la experiencia infantil del divorcio parental: importancia de los apoyos, los contactos con el progenitor no custodio y la calidad de las relaciones familiares: experiencia infantil del divorcio parental. Revista de Psicologia da Criança e do Adolescente, 6(2), 13-29.

Moscoso, L. L., \& Díaz, H. L. (2018). Aspectos éticos en la investigación cualitativa con niños. Revista Latinoamericana de Bioética, 18(1), 51-67. https://doi.org/10.18359/1lbi.2955

Neiman, G., \& Quaranta, G. (2009). Los estudios de caso en la investigación sociológica. En I. Vasilachis (Coord). Estrategias de investigación cualitativa. Gedisa.

Núñez, A. L., \& Vallejo, T. M. (2019). El reflejo de la realidad actual de nuestros menores ante el divorcio. Revista de Estudios Socioeducativos, 7(11), 166-174. https://doi.org/f8q3

Nuñez, M., Pérez, C., \& Castro, P. (2017). Consecuencias del divorcio-separación en niños de edad escolar y actitudes asumidas por los padres. Revista Cubana de Medicina General Integral, 33(3), 296-309.

Pérez, D., \& Luján, I. (2015) Percepción de niños de contextos rurales y urbanos sobre separación y divorcio. Infad. Revista de Psicología, 1(1), 285-296. https://doi.org/f8q4

Rovetta-Cortés, A. I. (2017). «Si me dieran un billete de avión...»: recurriendo a la elucidación gráfica en entrevistas con menores de edad. Empiria. Revista de Metodología de las Ciencias Sociales, (36), 63-87. https://doi.org/10.5944/empiria.36.2017.17859

Sánchez, Y. T., \& Bolaños, C. I. (2018). El trabajo conjunto de profesionales del derecho y la psicología: una forma de minimizar las consecuencias negativas del divorcio en los hijos. Psicopatología Clínica, Legal y Forense, (18), 31-40. 
Smart, C. (2006). Children's narratives of post-divorce family life: From individual experience to an ethical disposition. The Sociological Review, 54(1), 155-17o. https://doi.org/ 10.1111/j.1467-954X.2006.00606.x

Sosenski, S. (2016). Dar casa a las voces infantiles, reflexiones desde la historia. Revista Latinoamericana de Ciencias Sociales, Niñez y Juventud, 14(1), 43-52.

Stake, R. (1999). Investigación con estudio de casos. Morata.

Thomas, D. (2020). Who am 'I': Reauthoring self, stories, and subjectivity in research with children. Global Studies of Childhood, 11(13), 1-15. https://doi.org/f8q5 